\title{
Adoption of Innovation in Small-Scale Forestry: The Case of Portable-Sawmill-Based Microenterprises
}

\author{
Crystal Lupo \\ Rutgers University
}

\begin{abstract}
Microenterprise development can be a valuable societal component not only in terms of filling important niche markets, but also by enhancing a society's wellbeing through creating opportunities available to people who are marginalized by the labor force for one reason or another. Forest microenterprises, in particular, can enhance rural community development efforts, as well as forest conservation goals, by empowering local people to successfully manage their resources as well as offer the possibility of income enhancement (Salafsky, Cordes, Leighton, Henderson, Watt, \& Cherry, 1997; Lupo, 2012). This paper explores the adoption of portable-sawmill-based forest microenterprises. Key findings include common factors motivating portable sawmill adoption, as well as a bimodal adoption pattern, supporting previously postulated arguments regarding the importance of creating multiple adoption theories.
\end{abstract}

Keywords: forest microenterprises, small-scale forestry, portable sawmills, rural community development, adoption of innovations

\section{Introduction}

Microenterprises can add valuable resources to the larger society, both in terms of filling important markets often outside the scope of mainstream industry and by enhancing a society's wellbeing through reduction of poverty, creating opportunities available to people who are marginalized by the labor force for one reason or another. Forest microenterprises, in particular, can be beneficial to enhancing community development efforts as well as forest conservation goals, empowering local people to enhance their own income as well as manage their resources (Salafsky, Cordes, Leighton, Henderson, Watt, \& Cherry, 1997). This, in turn, can lead to positive social change by allowing rural residents with limited alternatives the opportunity to earn income while contributing to local community development.

This paper discusses the innovation process for portable sawmill entrepreneurs, an important piece to understanding the adoption process, answering the question of what motivates individuals to adopt portable sawmills. Over the past 50 years, adoption research has focused a great deal of attention on the process an individual goes through when choosing to adopt a new technology; however, given the abundance of technologies flooding the market today, the "hows and whys" in terms of technology adoption become a particularly important issue (Straub, 2009). Understanding why an individual does something, or adopts an innovation or technology, is pivotal to understanding the larger picture regarding development and extension strategies aimed at helping others to realize the same potential. In addition, the bimodal adoption pattern revealed in this study is an interesting contribution to adoption research and could be useful in understanding future patterns of adoption. 
Lupo, 2015

\section{Literature on Adoption of Innovations}

When attempting to introduce any new technology or process into a community, it is important to understand how people obtain information about, respond to, and adopt or reject the innovation. This is known as the adoption and diffusion of innovations. Rogers (1995) defines an innovation as "an idea, practice, or object that is perceived as new by an individual or other unit of adoption" (p. 11). There is little importance given to whether the innovation is actually or objectively new; it matters only if the innovation is perceived as new to the individual (Rogers, 1995). Therefore, a new technology or innovation need not be actually new; instead, the technology can be new in the eyes of the adopter, but not necessarily new to society. Instead, simply the "perception of novelty" in either an abstract or concrete form is sufficient (Straub, 2009).

It is in this sense that adoption theory is applicable to this study of portable sawmill microenterprises and adds to the literature on the adoption/diffusion model. Portable sawmills are not a new technology. Instead, the implementation of the use of portable sawmills or other smallscale harvesting and processing technologies to diversify the economies of forest-dependent communities might be new to residents who have few other options available to them. The perception of the innovation is an important factor, as the same innovation can mean different things depending on the context in which it was presented (Adams, Tranfield, \& Denyer, 2011).

The application of current adoption theory is historically rooted in the results of one of the most influential adoption/diffusion studies in rural sociology - the Ryan and Gross (1943) hybrid corn study, followed by an Iowa extension publication in 1950. Ryan and Gross's (1943) study on the adoption and diffusion of hybrid corn reflects the adoption of a new technology that fundamentally changed farming practices. This is conceptually very different than the adoption and diffusion of small-scale forest technologies, such as portable sawmills, in that there is not an expectation that all, or even a majority, of people will adopt this technology. The fundamental objective in utilizing the traditional adoption theory in this research is to try to identify adoption characteristics of portable sawmill adopters using the traditional framework developed by Ryan and Gross (1943), and expanded by others in the contemporary adoption literature, in order to identify and subsequently target appropriate extension services to those who might benefit from utilizing this technology to bring about positive social change in terms of rural community development.

Rogers (1995) identified five categories of adopters within the innovation design process: innovators, early adopters, early majority, late majority, and laggards. Each of these categories of adopters undergoes a process of obtaining knowledge about an innovation, forming a favorable or unfavorable attitude toward it, a decision to actually adopt or reject the innovation, implementing the innovation into their lives, and confirmation seeking to reinforce their decision.

In populations that are characterized as rural, residents are more likely to have lower educational levels; therefore, the particular innovation's complexity is an important factor in decisions to adopt that technology (Fliegel \& Kivlin, 1966). To the extent that portable sawmills are a technology with rural roots, this finding may be of importance to the current study. While there are economic barriers to adoption (Aikens, Havens, \& Flinn, 1975), small landowners are responsive to financial incentives and information dissemination, which can overcome documented adoption deterrents such as low educational attainment (Dadi, Burton, \& Ozanne, 2004; Carletto, Angeli, \& Winters, 2010; Hooks, Napier, \& Carter, 1983; Nowak, 1987; Calatrava \& Franco, 2011). 
Contemporary research defines adoption as an inherently social, complex, developmental process influenced by unique, but malleable, perceptions of the particular technology (Straub, 2009). Contextual, emotional, and cognitive concerns should be addressed when successfully facilitating a technology adoption and should serve as the general direction for understanding technology adoption (Straub, 2009). Portable sawmill adoption outlined in this exploratory study describes the unique process respondents went through in their decision to adopt portable sawmills, as well as the complexities of those decisions.

\section{Method}

This study utilized a qualitative research design with a total of 30 participants selected based on results they provided in a previously completed national portable sawmill survey. Participants indicated in the initial survey that, if elected, they would participate in follow-up interviews.

Interview questions primarily focused on adoption variables used to understand how the innovation process began for the individual, why respondents chose to adopt a portable sawmill as part of a forest microenterprise, and the S-shaped rate of adoption among owners. If respondents were part of

a niche market, additional questions attempted to uncover how the entrepreneur was able to identify this market and what steps needed to be taken to enter into it.

Initial contact with interview respondents was made via the telephone, email, or U.S. mail, depending on the information they provided on the survey. The form of these interviews was most often telephone conversations due to the fact that respondents were geographically located throughout the United States. However, a few respondents preferred to be contacted through email due to scheduling conflicts. Regardless of the mode of interview (telephone or email), the interview questions, question order, and follow-up clarifications remained the same to ensure uniformity in the responses. Each interview lasted between $20 \mathrm{~min}$ and $2 \mathrm{hr}$, with the average length of an interview being approximately $45 \mathrm{~min}$. Lack of regional variation in the larger survey data analysis led to a reasonable expectation of a similar outcome in the interview data as well. Therefore, the interview data was explored on an aggregate level without regard to U.S. region.

The interview responses were qualitatively analyzed to understand how respondents' use of portable sawmills was adopted and later diffused throughout their communities. Qualitative analysis was also used to understand portable sawmill owners' innovation processes and later categorize them into common themes. Interview responses regarding general adoption rates as well as portable sawmill adoption were coded and matched with categorical attributes within the traditional adoption model, to obtain an understanding of portable sawmill microenterprise owners' rates of adoption.

\section{Results}

Portable sawmill adoption research presented in this study uses the traditional adoption model, contributing to it its significance, as well as giving new application to the model. A significant finding in this research rests not only in the uniqueness of portable sawmill adoption as a whole as compared to the traditional model, but also in that a bimodal adoption pattern emerged between those who utilized their portable sawmill as part of a full-time microenterprise and those who used their mill as a part-time microenterprise. Given the existence of this bimodal adoption pattern, extension and other rural development programs should recognize these differences in adoption and develop their programs accordingly. 
Straub (2009) notes, "whereas the results of adoption theory are measured in terms of behavioral change, the predictors of that behavioral change can be understood through contextual, cognitive, and affective factors" (p. 627). While the emergence of a bimodal pattern was a significant finding between full-time and part-time portable sawmill microenterprise owners, there was no difference in way the innovation process began, or in why respondents chose to adopt a portable sawmill, based on their full-time or part-time status.

\section{How the Innovation Process Began: The Adoption of Portable Sawmilling}

Portable sawmills have been around for centuries. Philip (2001) noted that this technology was initially developed during Egyptian pyramid building, refined by the Romans, and reinvented in the 19th century during the industrial revolution using water and steam; it was later modified into gasoline-, diesel-, and electricity-based circular, band, and chainsaw mills of today.

Previous adoption studies focused on this type of innovation reinvention, or adopting an already existing innovation after modifying it in some way to meet the adopter's needs (Rogers, 1995). For

several of the portable sawmill owners interviewed, their innovation process began while attempting to find other income revenue streams for an existing business or to supplement their regular fulltime careers. Many respondents had been engaged in forestry-/wood-working-based interests for many years before becoming interested in portable sawmills. Common themes emerged as portable sawmill owners discussed their primary reasons for entering into a small-scale forest microenterprise utilizing portable sawmills: as a way to expand a farm business, as a conservation effort, and as a way to fill a needed niche market. One of the most interesting aspects of the themes that has emerged, and in portable sawmill culture in general, is that it tends to transcend locality in that portable sawmill owners around the country are doing the same types of things with their mills for the same group of reasons despite regional or other locality differences.

A major hindrance to adoption of new innovation is lack of economic resources to do so (Ryan \& Gross, 1943; Aikens et al., 1975; Rogers, 1995). Cost played a varying role in microentrepreneurs' decisions on whether to purchase a mill as well as what type of mill to purchase. To some, the cost factor was the most important factor regardless of the actual cost of the mill, which ranged from under $\$ 5,000$ to some within this category to well over $\$ 40,000$ to others. Likewise, some who purchased mills within this same range did not consider cost to be a factor. For most, however, cost tended to be a fairly large or very critical part of the actual mill they purchased and there was little difference in the importance of cost between part-time sawyers and full-time sawyers (Table 1; Lupo, 2012). 
Lupo, 2015

Table 1: The Role of Cost in a Decision to Purchase a Mill

\begin{tabular}{lccc}
\hline \multicolumn{1}{c}{ Role of Cost } & $\begin{array}{c}\text { Full-Time } \\
\text { Sawyer (\%) }\end{array}$ & $\begin{array}{c}\text { Part-Time } \\
\text { Sawyer (\%) }\end{array}$ & $\begin{array}{c}\text { Combined } \\
(\%)\end{array}$ \\
\hline $\begin{array}{l}\text { Not important, "features more important than } \\
\text { cost" }\end{array}$ & 7 & 10 & 17 \\
Fairly important & 7 & 16 & 23 \\
Big factor, "this was a major expense" & 20 & 23 & 43 \\
$\begin{array}{l}\text { Big role, "I wish I spent more to get a better } \\
\text { mill" }\end{array}$ & 0 & 7 & 7 \\
$\begin{array}{l}\text { Major factor, "I bought the cheapest mill for } \\
\text { what I needed" }\end{array}$ & 7 & 3 & 10 \\
\hline
\end{tabular}

The role of cost, in general, can have fairly important implications as to the initial commitment of the entrepreneur to the innovation (in this case, the portable sawmill). For example, some respondents indicated that they were willing to "jump in with both feet," while others wanted to "test the waters" with a less expensive mill before purchasing a more expensive model. The role of cost is also illustrative of the socioeconomic characteristics of portable sawmill. Full-time sawyers tended to have a lower household income when compared with part-time sawyers, and for those with lower incomes, cost can be an overwhelming factor preventing adoption. Extension programs or other rural development initiatives should target ways to assist would-be portable sawmill adopters to obtain the funds to purchase a mill. This assistance could come in the form of education on low-interest loans or grants available to help fund their purchase, as well as programs designed to educate adopters and would-be adopters on budgeting, itemizing expenses, and other financial activities to allow the best chance for them to achieve success in their microenterprise.

\section{Time and the S-Shaped Rate of Adoption}

Portable sawmill owners interviewed had various perceptions of how innovative they are in terms of their rate of adopting new technologies in general (Figure 1; Lupo, 2012). Despite these differences, they often considered themselves innovators both in the forest products sector as well as in life.

Several respondents noted the fact that they understand that technology improves productivity, pointing out that they are innovative in both their home life and careers. As one respondent indicated, "I used to design experimental equipment so I am well skilled in figuring out whether to get on the bandwagon." A different respondent stated, "I am not skeptical at all. If I am not innovating I'm checking out to see who's innovating-once an engineer, always an engineer." Another respondent with an engineering background offered a similar response, "I have a background in mechanical engineering and aerospace so I am interested in innovations." Not only was the sense of innovation seen in mechanical fields, but also in service-oriented fields, such as with this high school teacher who stated, "when I see something in a magazine, if I cannot afford to buy it I figure out how I can make it." 


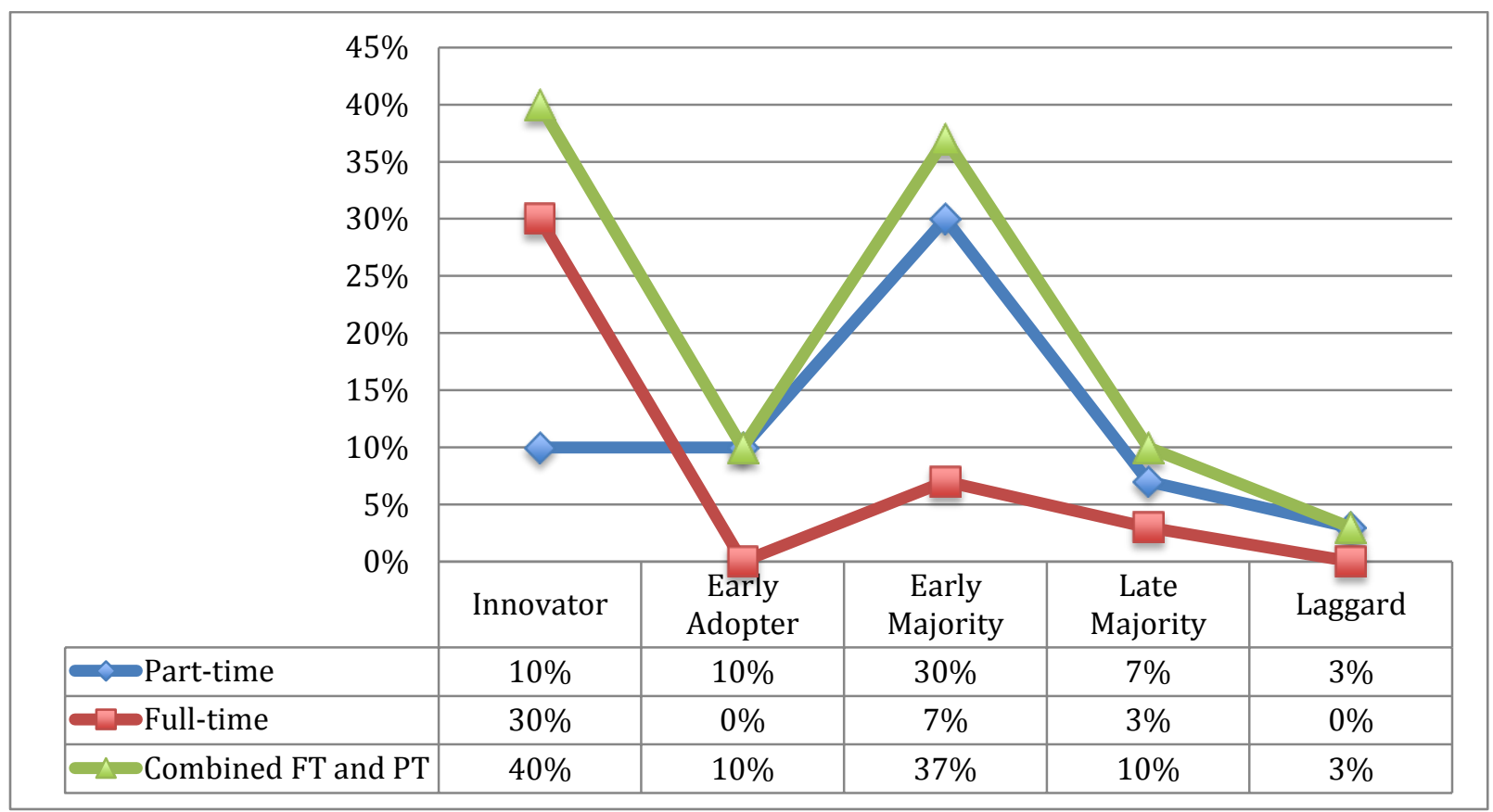

Figure 1: Self-Perception of Portable Sawmill Adoption, or "General Adoption Rate"

In connecting portable sawmill adoption rates with Roger's (1995) adoption model, a key difference between traditional adoption models and this study becomes obvious, as it is not expected that an entire population —or even the majority of a population, for that matter-would adopt portable sawmills. Despite this difference, categorical descriptions of the adoption model are still usable, though in a slightly different way, specifically in describing key sets of characteristics that can help to describe portable sawmill microenterprise owners. In other words, it can help explain and describe characteristics on the type of individuals that portable sawmill microenterprise owners are. The implications of this are important in targeting extension service or other rural development models to would-be portable sawmill populations.

When looking at the general adoption rates of portable sawmill owners (full-time and part-time sawyers combined) there appears to be an obvious divergence between Rogers' (1995) adoption model and the general adoption rate in this model. However, when analyzing the full-time and part-time sawyer categories separately, a new picture begins to emerge. In this model, part-time sawyers tend to be more of a fit with the traditional adoption pattern described in Rogers' model, whereas the fulltime sawyer group is innovatively quite different (Figure 2; Lupo, 2012). The differences in the general perceived adoption rate of full-time compared to part-time sawyers are significant $\left(\chi^{2}=\right.$ $11.02, p=.05$, Fisher's exact $=.015)$. Full-time sawyers interviewed tended to have a more innovative general adoption rate as compared with part-time sawyers, as well as traditional adoption models $(p=.05)$. Hence, the significance of extension or other development programs utilizing appropriate adoption models for the particular population subgroup is again evident (Figure 1; Lupo, 2012). 


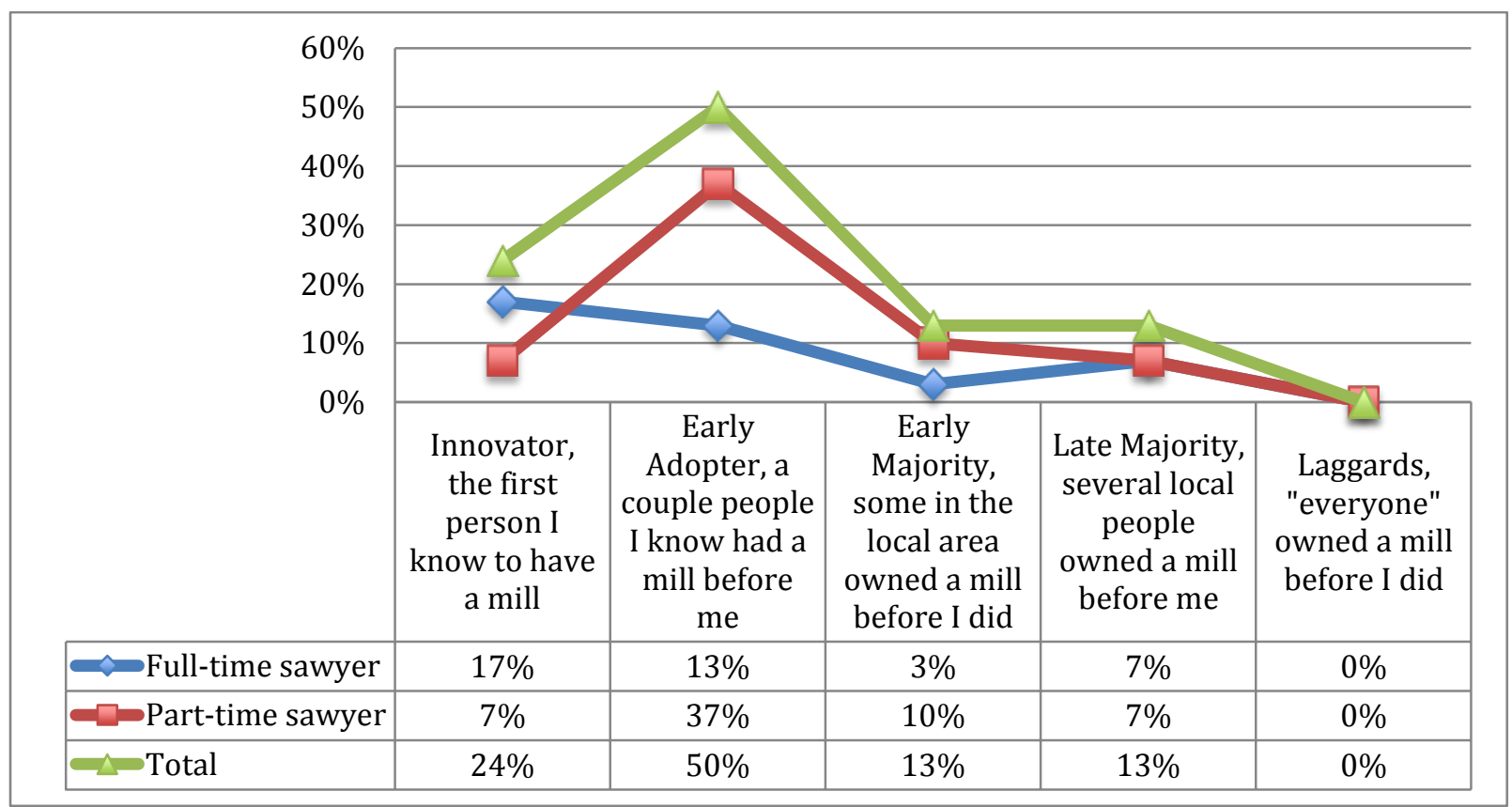

Figure 2: Portable Sawmill Adoption Rate Based on Presence of Mills in Sawyer's Local Community

Portable sawyers' perceived innovativeness did not follow the same curve as their actual rate of adoption. The majority of respondents made up the innovator (24\%) and early adopter (50\%) categories, which were among some of the first individuals in their local communities to own a portable mill; while another $13 \%$ made up the late majority (Figure 2; Lupo, 2012). Approximately $50 \%$ of the sawyers interviewed belonged to an early adopter group, where the respondent was still one of the first they knew to own a mill, but there was one or more people whom they knew of who owned a mill before them. This varied from the self-perception of their rate of adoption mentioned earlier, where only $10 \%$ concerned themselves early adopters. Likewise, full-time sawyers were more representative in the innovator group than any other. This finding was applicable in both the general adoption model and the portable sawmill adoption model. Part-time sawyers were slightly more apt to adopt a portable sawmill earlier than their general adoption rate.

There was a statistically significant correlation between the rate of adopting a portable sawmill compared with the rate of adopting new technologies in general $(p=.01)$ When comparing portable sawmill owners' perceived general adoption rate to their adoption of portable sawmills, a disparity becomes evident, resulting in opposite extremity points within the rates of adoption categories (Figure 3; Lupo, 2012). This disparity contributes to a weakened statistically significant linear relationship between the two. 


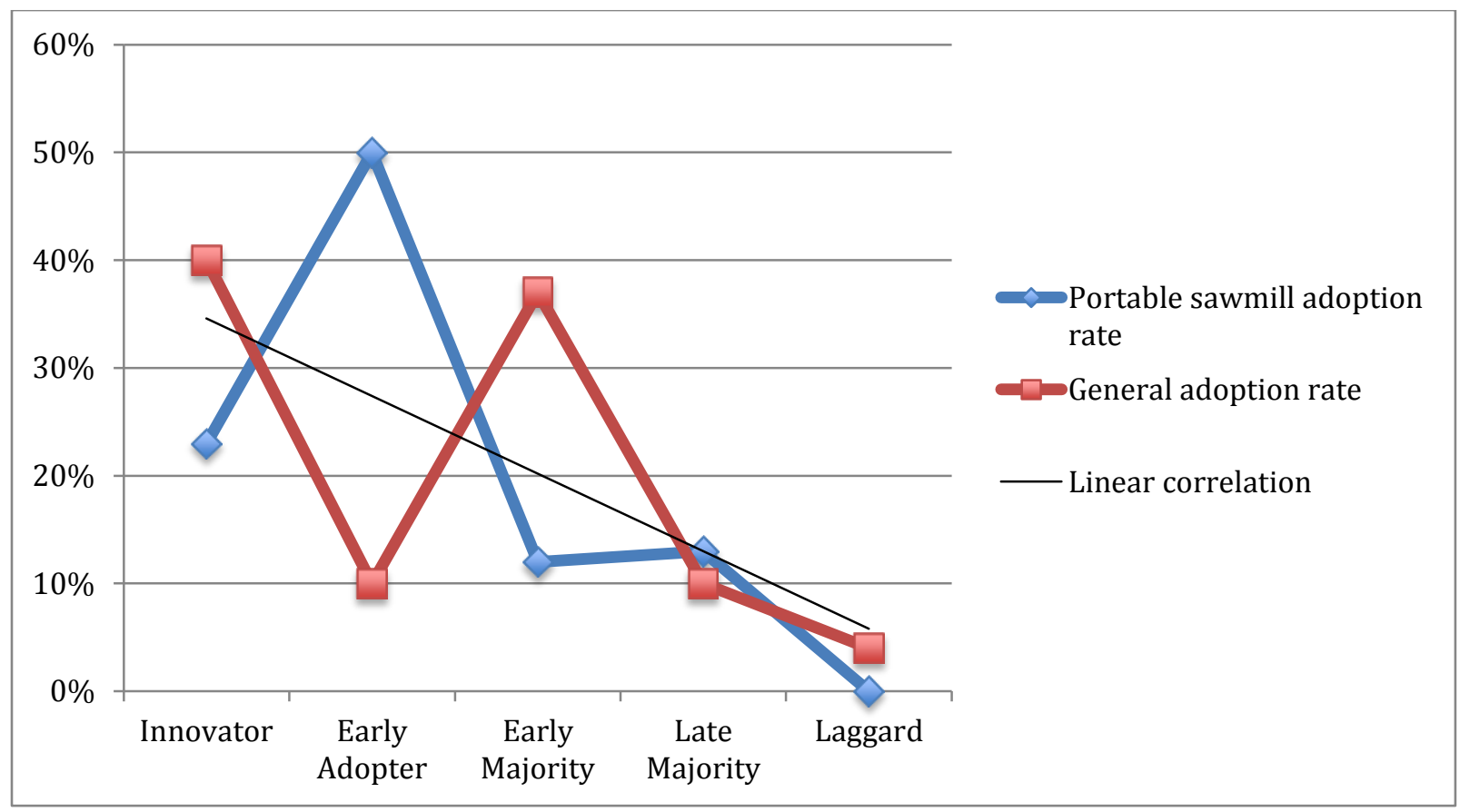

Figure 3: Correlation Between Self-Perceived General Adoption Rate and Portable Sawmill
Adoption Rate

Rogers (1995) depicted the cumulative length of time it took various populations to adopt an innovation as the S-shaped rates of adoption. Rogers (1995) notes, "most innovations have an Sshaped rate of adoption. But there is variation in the slope of the ' $\mathrm{S}$ ' from innovation to innovation ... Innovations that are perceived by individuals as possessing a greater relative advantage, compatibility, and the like, have a more rapid rate of adoption" (p. 23). The sawyers' perceived general adoption rates follow a very clearly defined and steep S-shaped curve. Likewise, full-time sawyers followed a more flatly defined S-shaped adoption curve (Figure 4; Lupo, 2012).

Part-time sawyers did not seem to follow as clearly defined of an S-shaped curve in their rates of adoption. The reason for this is not fully known, but one hypothesis is that portable sawmill owners tend to belong to more innovative adopter categories-or perhaps the technology is in its relative early stages of adoption and, therefore, the late majority and laggard groups are not fully represented and perhaps never will be, given the specialized and unique nature of a portable sawmill microenterprise. 


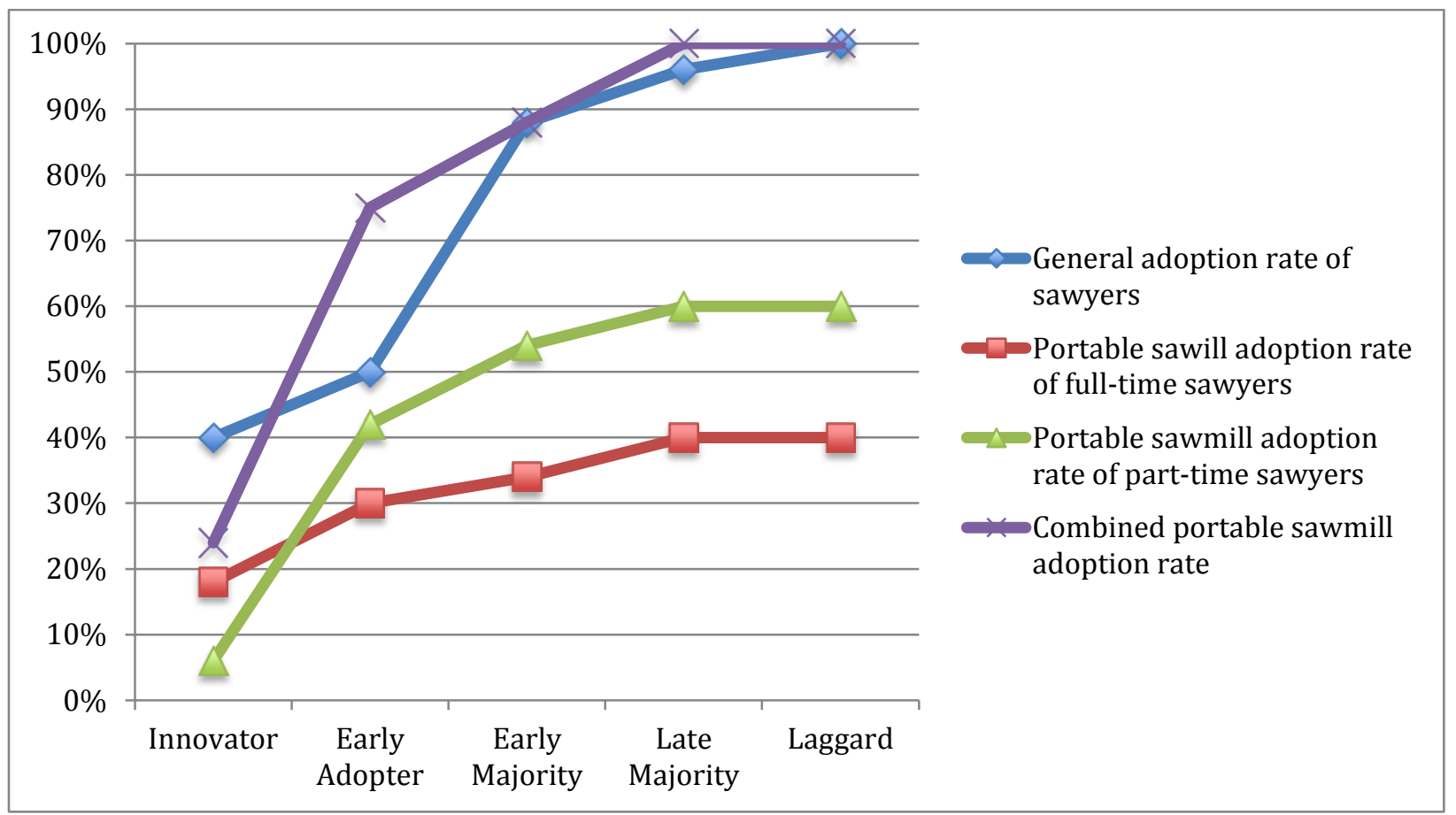

\section{Figure 4: Comparison of General Adoption Rate to Portable Sawmill Adoption Rate, in Full-Time and Part-Time Sawyers}

This anomaly in the adoption curve of part-time sawyers, in turn, altered the dynamic of the total portable sawmill adoption rate supporting the theories brought forth by Downs and Mohr (1976), who note the importance of postulating multiple theories of the adoption and diffusion of innovations based on the varying attributes of the innovations themselves. An important finding in this data suggests that not only are multiple theories of adoption and diffusion important based on attributes of the innovation, but also in the characteristics of the adopters themselves, as seen in the bimodal adoption patterns of portable sawmill owners.

\section{Discussion}

An important piece to understanding the adoption process is considering what influences individuals to adopt a new technology. Portable sawmill adoption was motivated by three common factors-as a way to expand a farm business, as a conservation effort, and as a way to fill a niche market. Attention should be focused on groups of individuals who fit these criteria, in the need to expand a farm, have an interest in conservation, and general entrepreneurial energy that could provide the motivation to enter a new niche market. All three of these areas have the potential to positively impact local communities and bring forth positive social change.

For the majority of portable sawmill owners (82\%), cost was a major factor in their decision to adopt a mill, and which mill they subsequently adopt. Programs could be designed to help potential adopters obtain funds to purchase a mill. These programs could be educational in nature, outlining low-interest loans or grant availability. Programs could also be designed around budgeting, 
expensing, and other financial management activities to enable the best chance for success in their adoption.

When comparing general adoption rates of portable sawmill owners with traditional adoption models, an obvious difference is evident, resulting in opposite extremity points between the traditional adoption model and the general adoption rate of portable sawmill owners. However, when examining part-time and full-time sawyers as separate groups, the innovativeness of part-time sawyers more closely resembles traditional models, whereas full-time sawyers tend to be, as a group, more innovative. Likewise, when analyzing the rates of portable sawmill adoption, part-time sawyers fit a traditional adoption model, whereas full-time sawyers were more innovative in their mill adoption.

An examination of the S-shaped rate of adoption among portable sawmill owners revealed that fulltime sawyers tend to follow a flatly defined S-shape, whereas part-time sawyers' cumulative adoption rates do not resemble the traditional S-shaped rate at all, even though an S-shaped adoption rate is evident in their general adoption rates. This finding further supports the need to differentiate theoretically between different types of innovations. This bimodal adoption pattern is a significant finding in this research and supports the importance of creating multiple adoption theories. This bimodal adoption pattern should be taken into consideration when creating programs for potential adopters.

\section{Conclusion}

The common themes that have emerged in the innovation process for portable sawmill owners, as well as bimodal adoption characteristics outlined earlier, have general applicability to research contribution in the field and have specific applicability as use as a tool or model to guide extension services or other rural development initiatives in promoting portable sawmill microenterprise development to the appropriate audiences. The effect of this can result in contributions to rural community development, as well as to larger positive social change in bringing about increased opportunities to rural areas where limited option might exist.

\section{References}

Adams, R., Tranfield, D., \& Denyer, D. (2011). How can toast be radical? Perceptions of innovations in healthcare. International Journal of Clinical Leadership, 17, 37-48.

Aikens, M. T., Havens, A. E., \& Flinn, W. (1975). The adoption of innovations: The neglected role of institutional constraints. Columbus, OH: Department of Rural Sociology, The Ohio State University.

Calatrava, J., \& Franco, J. (2011). Using pruning residues as mulch: Analysis of its adoption and process of diffusion in Southern Spain olive orchards. Journal of Environmental Management, 92, 620-629.

Carletto, C., Angeli, P., \& Winters, B. (2010). Globalization and smallholders: The adoption, diffusion, and welfare impact of non-traditional export crops in Guatemala. World Development, 38, 814-827.

Dadi, L., Burton, M., \& Ozanne, A. (2004) Duration analysis of technological adoption in Ethiopian Agriculture. Journal of Agricultural Economics, 55, 613-631. 
Downs, G., \& Mohr, L. (1976). Conceptual issues in the study of innovation. Administrative Science Quarterly, 21, 700-714.

Fliegel, F., \& Kivlin, J. (1966). Attributes of innovations as factors in diffusion. The American Journal of Sociology, 72, 235-248.

Hooks, G., Napier, T., \& Carter, M. (1983). Correlates of adoption behaviors: The case of farm technologies. Rural Sociology, 48, 308-323.

Lupo, C. (2012). The role of portable sawmill microenterprise adoption in promoting rural community development and its application in small-scale forest management. (Doctoral dissertation). Proquest; Umi Disertation Publishing.

Nowak, P. (1987). The adoption of agricultural conservation technology: Economic and diffusion explanations. Rural Sociology, 52, 208-220.

Philip, J. (2001, September). A brief history of portable sawmills. Retrieved from http://www.woodweb.com/knowledge_base/A_Brief_History_of_Portable_Sawmills.html

Rogers, E. (1995). Diffusion of innovations, 4th edition. New York, NY: The Free Press.

Ryan, B., \& Gross, N. (1943). The diffusion of hybrid seed corn in two Iowa communities. Rural Sociology, 8, 15-24.

Salafsky, N., Cordes, B., Leighton, M., Henderson, M., Watt, W., \& Cherry, R. (1997). Chainsaws as tools for conservation? A comparison of community based timber production enterprises in Papua New Guinea and Indonesia. Rural Development Forestry Network Paper $22 b$. Retrieved from http://www.odi.org/sites/odi.org.uk/files/odi-assets/publications-opinionfiles/1166.pdf

Straub, E. (2009). Understanding technology adoption: Theory and future directions for informal learning. Review of Educational Research, 79, 625-649.

The Journal of Social Change, sponsored by Walden University, welcomes manuscripts focusing on interdisciplinary research in social change that improves the human condition and moves people, groups, organizations, cultures, and society toward a more positive future.

Walden University Publishing: http://www.publishing.waldenu.edu 